\title{
Sentido eclesiológico del patrocinio de los santos
}

\author{
Ecclesiological Sense of the Patronage of the Saints
}

\section{Piotr RosZAK}

Uniwersytet Mikołaja Kopernika. Wydział Teologiczny

Toruń. Polonia

ID ORCID 0000-0002-2723-2667

piotrroszak@umk.pl

Resumen: En el artículo se presentan las bases eclesiológicas del culto de los santos patronos, y se pone de relieve la dimensión relacional del misterio de la Iglesia. Se presenta la idea teológica de la intercesión de los santos patronos acudiendo a dos observaciones de santo Tomás de Aquino: el don de ser «causas» del bien y la visión jerárquica del mundo. El patrocinio de los santos se manifiesta en su peculiar intercesión (siempre en contexto cristocéntrico), en su índole ejemplar para la vida cristiana, en su protección y acompañamiento como manera de concretar la universal solicitud de Dios por todo el universo.

Palabras clave: Patrocinium, Intercesión, Comunión de los santos, Tomás de Aquino, Liturgia hispano-mozárabe.
Abstract: The article presents the ecclesiological foundations of the veneration of patron saints and highlights the relational dimension of the mystery of the Church. The theological idea of the intercession of patron saints is exposed by referring to two observations of Saint Thomas Aquinas: the gift of being the «causes» of good and the hierarchical vision of the world. The saints' patronage is manifested in their special intercession (always in a Christocentric context), in the example they give for Christian life, and in their protection and accompaniment as an embodiment of God's universal solicitude towards the whole universe.

Keywords: Patrocinium, Intercession, Communion of Saints, Thomas Aquinas, Hispanic-Mozarabic Liturgy. 


\section{INTRODUCCIÓN}

E $\mathrm{n}$ los trabajos de los historiadores se observa a veces un tono sospechoso respecto del culto de los santos en la Iglesia, donde se detecta una cierta confusión en torno a la correspondencia entre un santo y su «patrocinio». Todo parecería indicar que su patrocinio es mero fruto de una casual coincidencia si -por ejemplo- una de las herramientas de su martirio parece decidir el alcance de su patrocinio. No obstante, sigue siendo actual proclamar a un santo «patrono» de un país o de un grupo (p. ej. de scouts), o en la vida civil (Galileo como «patrón» de la ciencia, o en los nombres de las calles, etc.), ampliando considerablemente este concepto religioso. No abundan los estudios que profundicen lo específico de tener un patrón, aunque no faltan libros o léxicos sobre los nombres de los santos. ¿Qué significa teológicamente tener un santo como patrón? ¿En qué ideas teológicas se basa el «papel» que ejerce un santo? En este artículo vamos a combinar la perspectiva histórica (primera parte) con los contenidos teológicos que subyacen en esta venerable tradición cristiana que ya conoció santo Tomás de Aquino.

\section{Contexto antiguo del patronato y SU INFLUENCIA EN EL CULTO A LOS SANTOS}

Para exponer el contenido teológico del patrocinio, hay que mencionar el uso de este término en los primeros siglos del cristianismo, cuando se asumen las connotaciones romanas del patronus para expresar ideas fundamentales de la visión cristiana del mundo. En la Roma antigua, con el término patrocinium -derivado de pater- se indicaba la persona que con su influencia era capaz de proteger y asistir a quien se encomendaba a él, y que recibía como recompensa una serie de servicios, tales como honores (en la manera de saludarle, salutatio) o alabanzas ${ }^{1}$. En este marco conceptual se sitúa la raíz cristiana del patrocinio.

\section{a) Herencia del patronus romano en el culto de los santos}

El patrocinio en la sociedad romana era una red de relaciones (también heredadas) basadas en el acto definido como se commendare o se dare, y que constituía un fundamento de la vida social y también de la vida religiosa y do-

${ }^{1}$ Kaufman, R., «The patron-client concept, and Macro-Politics: Prospects and Problems», Comparative Studies in Society and History 3 (1974) 284-308. 
méstica de Roma. El patronus reflejaba una estructura social en la que se atribuía un gran papel a los jueces o defensores civitatis (locorum). El patrocinio sobre las cosas particulares llevaba a reconocer la potestad del patronus y encomendarse a ella. El patrón se comprometía actuar en nombre y defensa de los encomendados, y todos sus compromisos se contenían en el llamado ius patronatus. De ahí la formula primitiva in fide alicui esse, que reflejaba esa relación de dependencia y protección. En este sentido «estar en la fe de alguien» expresaba primordialmente la confianza en su protección, y la defensa ante los enemigos y en situaciones peligrosas ${ }^{2}$. Así la relación entre el patrón y el cliente en la sociedad romana mostraba un orden de relaciones constituidas en algunos casos en virtud del status social, o bien por libre decisión. No se trataba de una relacion entre iguales, pues la otra parte era el cliente o libertus o discípulo. En la época de Julio César ya no era una relación obligatoria, sino más bien voluntaria hacia aquellos ciudadanos de la república o del imperio respetados por sus méritos. Se trataba de actos de reconocimiento del estado de dependencia, desigualdad de las situaciones y potestades (potestas) ${ }^{3}$. Encomendarse al patrón suponía crear vínculos individuales que luego formaban la communio más amplia de la sociedad romana. El patrón ejercía la función de un mentor que recomendaba sus clientes para los oficios, y luego los acompañaba y aconsejaba en sus obligaciones ${ }^{4}$.

$\mathrm{El}$ acto de entrega a la protección del patrón se expresaba con la formula se commendare o commendatio, y a veces se realizaba también de forma escrita. Lo que se expresaba bajo ese título era una relación especial entre el patrón y cliente que superaba el mero interés individual: más bien, teniendo en cuenta que para los romanos el carácter de una persona se manifestaba mediante sus amigos (y su modo de tratarlos), la relación de patronato se inscribía en el marco de la amistad. Por ese motivo, no faltan testimonios de commendatio dirigidos a terceros que no se limitaban a enumerar rasgos objetivos del encomendado, sino

\footnotetext{
${ }^{2}$ Cfr. Badian, E., Foreign Clientelae, Oxford: Clarendon Press, 1958, 2. El autor menciona cuatro maneras por las cuales se constituía la relación de encomienda y confianza del cliente hacia su patrón; de entre ellas las dos primeras se basaban en el «estatuto» de la persona (liberación y herencia), y las siguientes se contraía en virtud de un «contrato» (deditio y applicatio).

${ }^{3}$ Cfr. CANALI DE Rossi, F., Il ruolo dei patroni nelle relazioni politiche fra il mondo greco e Roma in età repubblicana ed augustea, Munich-Leipzig, 2001. La posición clásica sobre el patronato en el mundo antiguo: Wallace-Hadrill, A., Patronage in Ancient Society, London: Routledge, 1989.

${ }^{4}$ SALler, R., Personal Patronage Under the Early Empire, Cambridge: CUP, 1982, 27, donde se subraya que la vigencia de la institución del patronato en la época del imperio se debía a la falta de administración.
} 
también a subrayar sus méritos y un trato familiar. El patrón escribía en nombre del cliente a un tercero para presentarlo y exponer sus méritos (también los de su familia). Estas relaciones del patrocinio no se ejercían únicamente respecto de las personas, sino también de las cosas e ideas; existían en el ejército romano y en la política (el patrocinio sobre Grecia, por ejemplo), para expresar la autoridad de Roma sobre las provincias conquistadas. Todavía en la época del imperio las ciudades elegían a los ciudadanos nobles e influyentes para que ejercieran de mediadores entre el consejo de la ciudad y el emperador ${ }^{5}$. Con el paso del tiempo, en momentos de guerras o de desintegración del Estado, la capacidad de protección ante el peligro se vinculaba con una postura ética ${ }^{6}$. En todo caso, lo característico del patrocinio era esa mirada hacia el futuro.

Ya en la Grecia antigua los héroes fueran proclamados patronos de las ciudades. Terminológicamente, el patrocinium comportaba, por tanto, ese «papel protector», análogo a los patronos romanos. En el ámbito cristiano se hará connotando la comunión de los santos?

\section{b) Translatio: desde el mundo civil al celestial}

El vocabulario antiguo, con sus metáforas, fue utilizado en el lenguaje cristiano posterior con un cambio de horizonte interpretativo: ya no se trataba de la sociedad civil, sino la sociedad de los santos. En este sentido san Ambrosio, en su comentario al Evangelio de san Lucas, veía a los mártires como los que ejercen su ministerio en favor de los que viven, a semejanza de los magistrados terrenos que representan en un territorio a la autoridad suprema (césar o rey $)^{8}$. Esta relación entre los santos y los fieles tenía un carácter casi jurídico, porque los santos y sus reliquias se convertían en garantías (pignora) de la protección divina. Un signo visible de esta intercesión como patrono era la presencia de sus reliquias en la ciudad o templos. De esta forma se convertía un santo en defensor y abogado (ad-vocatus, aquel a que se llama para la defensa); pero también se convertía en susceptor, es decir, el que apadrinaba a otro

\footnotetext{
5 TureK, W., «Patron saint», en Di Berardino, A. (ed.), Encyclopedia of Ancient Christianity, Downers Grove, IL: IVP Academic, 2014.

${ }^{6}$ Pocas veces se aplicaba en el mundo antiguo el título de patrón a los dioses (como en el caso de Venus, patrona de las sacerdotisas que ejercían su culto).

${ }^{7}$ Cfr. De Silva, D. A., Honor, Patronage, Kinship and Purity: Unlocking New Testament Culture, Downers Grove, IL: InterVarsity Press, 2000; OsIEK, C., «The Politics of Patronage and the Politics of Kinship: The Meeting of the Ways», Biblical Theology Bulletin 3 (2009) 143-152.

8 SAn Ambrosio, Expositio Evangelii secundum Lucam, 10,12 (CSEL 32,460).
} 
ante un tribunal. Cicerón menciona la asistencia de oradores pagados que defendían la causa de otro. Todo esto se reflejaba en la consideración de los santos como patroni en la corte divina, a veces a ejemplo de los aristócratas terrenos: se les consideraba como patres en virtud de su influencia, de una cierta jurisdicción y cuidado que ofrecían a los encomendados a su protección ${ }^{9}$.

Un autor que marcó un paso decisivo en esta «translatio», tan propia del mundo cristiano antiguo, es Paulino de Nola y su manera de presentar a san Félix como patrono de la ciudad de Nola (patronus caelis), si bien en sus escritos también mencionaba patronos de otras provincias (como san Martín para la Galia, o Delfinus para la Aquitania). La relación con el santo no se terminaba en la tierra, sino que se proyectaba a la vida celestial. Paulino la describía con la categoría de la relación entre alumno y maestro (alumnusmanicipium), como un libertus de los santos ${ }^{10}$. En el siglo $\mathrm{V}$ aparecen las Passiones donde se manifiestan muy frecuentemente los vínculos particulares entre determinados territorios y santos concretos. La relación de una ciudad con un santo se basaba en la conexión que tuvieron con ese sitio en virtud de su martirio o de su nacimiento, convirtiéndose ese santo en un peculiaris patro$n u s^{11}$. Algo similar sucedía en el caso de las iglesias que tomaban el nombre de un santo (su advocación) porque estaba sepultado en ellas, como en las iglesias del cementerio de Roma; costumbre que luego se extenderá a Milán (cuando se descubren los restos de los mártires, Gervasio y Protasio, Nazario y Celso, Vidal y Agrícola), sin olvidar la iglesia de Apostoleion en Constantinopla ${ }^{12}$. En el caso de no tener un santo patrón, el papel de protector de la ciudad lo ejercía su obispo, lo cual fue consolidado por la inclusión del obispo en el sistema jurídico del Imperio a partir de Constantino, e influyó en la manera de considerar su función en la Edad Media ${ }^{13}$. El papel protector del obispo no terminaba en la tierra, sino que continuaba desde el cielo.

\footnotetext{
${ }^{9}$ En este sentido, no extraña que la reacción protestante al culto de los santos patronos, tan visible en las decisiones del rey Enrique VIII de Inglaterra, era una protesta regia ante el modelo social que se apoyaba en los intermediarios y no en el poder absoluto del rey. No era un problema teológico, al parecer, sino más bien social. Cfr. Chapman, A. A., Patrons and Patron Saints in Early Modern English Literature, New York: Routledge, 2013, 2-3 (capítulo: The Patrons of Heaven and Earth).

10 Orselli, A. M., «Il santo patrono cittadino fra Tardo Antico e Alto Medioevo», en La cultura in Italia fra Tardo Antico e Alto medioevo, Roma: Herder, 1981, 771-784.

11 Lentino, F., «Patron», en Di Berardino, A. (red.), Encyclopedia of Ancient Christianity (2014).

12 Di Berardino, A., Diccionario Patrístico y de la Antigïedad cristiana, II, 1717.

13 BAjO, F., «El patronato de los obispos sobre las ciudades durante los siglos IV-V en Hispania», Memoria de Historia Antigua 5 (1981) 203-212.
} 
En la literatura medieval los santos actuaban también como aristocracia celestial sobre la que se apoyaba e imitaban los aristócratas terrenos (como se ve en la Canción de Rolando, o en el mismo Don Quijote).

Este contexto de analogías del imaginarium cristiano permitía expresar aspectos de la $\mathrm{fe}^{14}$ que se refieren a realidades transcendentes que superan la experiencia terrena.

c) Santos como patronos de las personas

En este ambiente estrictamente cristiano nació la práctica de atribuir el nombre de un santo a las personas, como confirman los textos patrísticos que mencionan el cambio de nombre de los conversos del paganismo, y también entre los mártires, tal como nos transmite Eusebio de Cesárea. Lo practicaban también los obispos de Roma al asumir la sede de san Pedro, como ilustra el caso del papa Juan II (533-535) que antes llevaba el nombre de Mercurio. San Ambrosio invitaba a seguir esta práctica a los padres de los niños que iban a ser bautizados para que de esa forma se pusieran bajo el amparo de los santos, y tuvieran un firme ejemplo en su camino de santidad. Todo esto promovía el gran papel del culto a los santos patronos ${ }^{15}$. No se trataba de oscurecer la función salvífica de Cristo, sino más bien de ofrecer ejemplos vivos de fidelidad evangélica para la vida cotidiana. La visión jerárquica del mundo, en su diversidad de ordines (como ilustra la idea de los coros angélicos), reflejaba la perfección de Dios y su manera de actuar en el mundo, iniciando al mismo tiempo un imaginario cristiano en el que los santos patronos expresaban la solicitud de Dios y los medios que Dios pone en el camino de salvación de los hombres.

\section{d) Patronus en la liturgia hispano-mozárabe}

Una simple mirada a la noción de patronus en la eucología del rito hispanomozárabe muestra el trasfondo teológico de las celebraciones de las fiestas de los santos patronos. En tales textos litúrgicos se subraya el estatuto ontológico de los redimidos que están coram Deo, y por ese motivo son capaces de ser gratiae

${ }^{14}$ Últimamente lo subrayaba MCGRATH, A. en su libro Re-imagining Nature. The Promise of Christian Natural Theology, Oxford: Wiley-Blackwell, 2017, desde la perspectiva de la teología fundamental, lo ha analizado STEEVES, N., Grâce a l'imagination. Intégrer l'imagination en théologie fondamentale, Paris: Cerf, 2016.

15 Brown, P., Il culto dei santi: l'origine e la diffusione di una nuova religiosità, Turin, 1983. 
providuus (S1326) ${ }^{16}$. Son patronos, como Santiago nobis patronus, a causa de ser discípulos de Cristo. Si ejercen de patronos celestiales (patronus in coelis) es porque han superado las tribulaciones y pueden comunicar los méritos (S1781). La liturgia descubre en ellos un patrón assiduus (S1827), como en el caso de san Cristóbal, al que se pide su protección frente a la corrupción del mundo. El patrocinio de los santos tiene esa dimensión defensiva: ayudar a los oprimidos y sufrientes. Es también significativo que la liturgia hispana vincule el patrocinio con un servicio de consolación, como en el caso de san Cucufato. Varios textos eucológicos hispanos mencionan la relación entre el santo patrón y los fieles como comunicación del «patrocinio» del santo: el pueblo de Dios se beneficia de lo alcanzado por el santo (sus méritos), que se comunica a los demás no sólo por título individual, sino en cuanto miembros de una comunidad unida con él por la fe. Es un reflejo de esa comunión de los santos o estrecha relación entre los santos y los fieles vivos: se fundamenta en el conocimiento que los santos poseen en el Verbo, mediante el cual conocen los asuntos de los fieles en la tierra y pueden socorrerlos como colaboradores de Dios que siempre quieren lo que Dios quiere ${ }^{17}$. Se trata de interceder por los vivos mediante una oración basada en sus méritos precedentes.

En la liturgia se contemplan los «méritos de los santos», que están a disposición de los todavía viatores. Las fórmulas son esclarecedoras a este respecto: cuius instructi patrocinio (M2230) o ut eius patricinio sublevetur (S1355), patrocinii sui nobis intercéssium apud eum (M2260). De modo que el patrocinio de los santos conforta, da ánimo (así cabe traducir el sublevetur) e instruye; los fieles se ponen bajo ese patrocinio (ut qui tuarum Virginum obsequimur patrociniis) y se enriquecen (Sanctorum suorum vos Dominus muniat patrocinio M2395), teniendo la seguridad de su asistencia (martyrum patrocinia nobis semper opitulentur). Por ejemplo, en la oratio admonitionis de la Misa en honor a san Vicente se explica el peculiar vínculo entre el santo y su intercesión por la Iglesia local:

Él, que con su patrocinio y su título glorioso de mártir levantó al pueblo al que enseñaba por encima del suelo paterno. Él permanece como gran protector, por designio divino, pues Dios le había prometido darle por ornamento a los pueblos a los que pertenecía, para que fuese

${ }^{16}$ Las siglas según TONiolo, A., Arocena, F. M. e IVORRA, A., Concordantia missalis hispano-mozarabici, Roma: LEV, 2009.

17 Martínez, M. A., «Estados o fases de la Iglesia», en Villar, J. R. (coord.), Diccionario de Eclesiología, Madrid: BAC, 2016, 562. 
también él su adorno; él conduce su devoción a Dios, dándose como rehén de los mismos ${ }^{18}$.

En esta oración introductoria de la Misa en el rito hispano, que siempre indica el motivo de la celebración, es interesante el papel del patrón que se expresa con el término de «rehén» del pueblo que está en marcha hacia la patria y que espera a los suyos como un adorno de su felicidad. Encomendarse al patrón -como se hace en diversas oraciones de este rito- manifiesta el deseo de sumarse algún día a su compañía en el cielo (ut illorum consortio adunemur in celis, quorum bic obsequimur patrociniis ${ }^{19}$ ). Como indica el término consorte, se trata de compartir la misma «suerte», es decir, participar de la misma felicidad.

Tal participación en la victoria de los mártires motivaba a los primeros cristianos a llevar el mismo nombre del santo. La fuerza de la intercesión deriva de la cercanía de estos santos a Cristo, y por eso se trata de enraizarse cada vez más profundamente, de manera litúrgica, en la obra redentora de Cristo y participar de sus frutos. Una clara muestra de ello la encontramos en la liturgia, por ejemplo en el oficio de la dedicación de iglesias (ordo dedicationis ecclesiae et altaris). En la liturgia romana el depósito de las reliquias en el altar constituía en sentido estricto su dedicación. Cuando faltaban las reliquias se utilizaba algún material que había estado en contacto con las reliquias del mártir o con sus cenizas ${ }^{20}$. En tales ritos se expresaba la fe en la presencia del santo y su fuerza de protección, lo cual venía subrayado mediante la denuntiatio del obispo, es decir, su explicación del sentido de estos ritos ${ }^{21}$.

\section{RAÍCES ECLESIOLÓGICAS DEL PATRONICINUM}

Tras analizar la transformación de la noción antigua de patrón en el patrocinium cristiano visigótico, veamos otros elementos utilizados en la idea cristiana del patrocinio de los santos respecto de las personas o de las cosas.

${ }^{18}$ In diem sancti Vincentii, diaconi et martyris, oratio admonitionis: «[...] Qui genitális soli alúmnam plebem, et patrocínio eréxit et título. Magnus confidéntia divína protectiónis exsístens, qui vernáculos pópulos ornatúrus asséreret, assertúrus ornáret; qui eórum devotiónem Deo ingéreret, quorum óbsidem se dedísset».

${ }^{19}$ In diem sancte Cecilie, virginis et martyris, alia.

${ }^{20}$ Les Ordines romain du baut moyen-âge, ed. ANDRIEU, M., Louvain, 1931-1957, t. IV, 364-368.

21 SzCZANIECKI, P., Sacramentum dedicationis. Obrzęd poświęcenia kościoła i jego znaczenie w dziedzinie religijnej, obyczajowej i kulturalnej na podstawie źródet polskich z XII wieku, Lublin: TN KUL, 1979, 42. 
Aparece este aspecto ya en el siglo II (Actus Petri cum Simone), y se acrecentó con el desarrollo del culto de los santos, con la atribución de una relación de los santos con grupos concretos de personas, o en relación con determinadas necesidades. Este segundo caso dio lugar al culto de los «santos auxiliares», es decir, un grupo de santos de los que los fieles esperaban ayudas específicas, también para necesidades físicas ${ }^{22}$. Este desarrollo histórico ayudaba a expresar en términos familiares el misterio de la fe cristiana ${ }^{23}$. Canónicamente, el modo de elegir los patronos fue establecido por el papa Urbano VIII en el año 1630, cuando indicó que el patrón debía estar canonizado, elegido por el pueblo y confirmado por Roma. Estas reglas fueron incluidas luego en el primer Código de Derecho Canónico en 1917 y concretado en 1973 por un decreto de la Congregación para el Culto Divino.

\section{a) Consecuencias de communio sanctorum}

El fundamento teológico del patrocinio de los santos se basa en la naturaleza comunional de la Iglesia, que implica la interacción entre todos sus miembros tanto en su estado in via como in patria: uno puede actuar en nombre de otro ante Dios, porque forman parte del mismo cuerpo, en el que no todos los miembros tienen la misma función (cfr. 1 Cor 12). Es consecuencia de comprender la Iglesia como «comunidad», es decir, que supone una communicatio entre sus miembros ${ }^{24}$. La comunión de los santos se basa en la pertenencia a la misma Iglesia en sus dos estados: militante y triunfante, peregrina y escatológica. En el Apocalipsis de Juan los acontecimientos en la tierra y en el cielo tienen lugar en una misma sala amplia, donde no hay nada privado: las oraciones de los santos suben, a través del servicio de los ángeles y los ancianos, ante el trono de Dios (cfr. Ap 5,8; 8,3). San Pablo afirma en la carta a los Efesios, que los fieles

22 BEINERT, W., «Saints, Veneration of», en The Encyclopedia of Christianity, vol. 4, Grand Rapids, MI: William B. Eerdmans Publishing Company, 2005, donde enumera el listado de 14 patronos para diferentes enfermedades.

23 Tiene que ver esto con la fundamental intuición de que naturaleza y gracia no están en relación dialéctica, la gracia no anula la naturaleza, sino que la gracia asume y transforma (sana y eleva) la naturaleza. De ahí que merece la pena fijarse en los elementos doctrinales que sostienen la idea cristiana de un santo patrón. Más en RoszAK, P., Credibilidad e identidad. En torno a la teología de la fe en santo Tomas de Aquino, Pamplona: Eunsa, 2014.

${ }^{24}$ KASPER, W., «Iglesia como communio», en IDEM, Teología e Iglesia, Barcelona: Herder 1989, 395. Cfr. también BERRY, J. A., «What make us human? Augustine on interiority, exteriority and the self», Scientia et Fides 2 (2017) 87-106. 
son co-ciudadanos del cielo (cfr. Ef 2,19). Según la expresión de Hans Urs von Balthasar, no sólo el suelo del cielo es de cristal transparente, sino también sus paredes ${ }^{25}$. También las Iglesias ortodoxas del oriente cristiano viven esta convicción de la ayuda fraterna de los santos como consecuencia de la comunión. Con ello la fe cristiana subraya la dimensión comunitaria de la salvación, por la cual cada uno es corresponsable del camino de fe del otro: Dios quiso ofrecer la salvación en forma comunitaria, formando un Pueblo (cfr. LG 9).

El patrocinio traduce esta «interdependencia» concretada en los santos protectores de la familia, de las casas, ciudades o actividades. Como el «cliente» en la sociedad antigua no poseía la ciudadanía romana, y se veía obligado a relacionarse con un patrón que le ofrecía la ayuda legal, análogamente siendo ciudadanos del cielo, los fieles que peregrinan en la tierra todavía estamos fuera del pleno derecho de ciudadanía celestial, que ya ha comenzado germinalmente en la tierra (inchoatio), pero que se cumplirá plenamente en la Patria. Así que el santo patrón no sólo nos protege del peligro en el camino, sino que nos lleva a la plena posesión de la ciudadanía del cielo.

\section{b) La gracia de ser una «causa»}

Otro punto doctrinal relacionado con la idea de patrocinio tiene que ver con la idea de intercesión que sucede en la vida de la Iglesia, y que se relaciona con el modo como Dios «gobierna» el mundo.

Es conocido el amplio debate contemporáneo sobre el llamado divine action project, es decir, sobre la intervención de Dios en el mundo. Sobre este tema santo Tomás de Aquino exponía la relación entre Causa Primera y las causas segundas de tal forma que Dios en su omnipotencia, aunque podría hacer todo, concede sin embargo a la criatura la gracia de ser «causa» del bien. Este modo de proceder no limita a Dios, sino que muestra su peculiar modo de actuar que sucede a través de causas segundas, que no pierden su identidad, ya que no compiten con Dios en el plano causal. Todo ello muestra la bondad de Dios y su pedagogía, según la cual las cosas se llevan a cabo no por causas remotas, sino próximas, permitiendo a la naturaleza -fruto del acto creador de Dios y expresión de su amor- actuar según su propia índole ${ }^{26}$. Ser causa del

${ }^{25}$ VON Balthasar, H. U., Kim jest chrzésíijanin?, Kraków: WAM, 1999, 109.

${ }^{26}$ Cfr. S. Th., I, q. 22, a.3c: «Esto es así no por defecto de su poder, sino por abundancia de su bondad, que transmite a las criaturas la dignidad de la causalidad». 
bien en la vida de otros es, en esta perspectiva, un reflejo divino y el modo de ejercer la providencia en la historia.

Con este fondo teológico se puede comprender la importancia de la noción de persona mystica que profundizó la Escolástica: en ella se muestra la codependencia tanto en el plano vertical (con la cabeza que es Cristo) y horizontal (entre los fieles). A la luz de esa aproximación teológica el papel del patrocinio de los santos no goza de autonomía, sino que se inscribe en el plan de Dios según el cual unos son para otros causas segundas -dependientes de la Causa primera- del progreso en el camino de la salvación. Dios quiere que los santos se auxilien recíprocamente por medio de la oración. La base teológica de esta intercesión es la koinonia o comunión en Cristo que une los fieles en la tierra con los santos del cielo, tal como lo expresa Heb 12, 22-24; es una «comunión operativa» entre los miembros del mismo Cuerpo en sus diferentes fases o estados ${ }^{27}$. La intercesión de los santos es un caso singular de la comunión en la Iglesia, donde todo dimana de su Cabeza, Cristo, que alcanza a todos también mediante sus miembros.

\section{c) La Iglesia como comunión de «relaciones»}

El estatuto de los santos y en particular su patrocinio refleja que la Iglesia es ante todo una red de relaciones de todos con Cristo y entre sus miembros. La personalidad de la Iglesia o «con-vocación» (kahal) de Dios, se expresa así en términos relacionales (escuela medieval de san Víctor).

Si retornamos al origen histórico del patronato -que era el ambiente que se respiraba en el Imperio romano, y que se refleja en el Nuevo Testamento, en particular en las cartas de san $\mathrm{Pablo}^{28}$ - aparecen algunas ideas para la com-

27 Esa conciencia se ve reflejada al tratar de dos collegia de los santos: cfr. TOMÁs DE AQUINO, In Psalmum 19, n. 1: «Secunda causa, mittat tibi auxilium de sancto, idest de collegio sanctorum. Et est duplex collegium sanctorum. Unum regnantium cum Deo in gloria; aliud est militantium in terra; et ex utrisque adjuvamur, quia Angeli intercedunt pro nobis: 2 Jo. 1: advocatum habemus, scilicet collegium Angelorum: Apoc. 8: ascendit fumus incensorum de orationibus sanctorum de manu Angeli, coram Deo».

${ }^{28}$ Es la tesis que desarrolla CroOK, Z. en su Reconceptualising Conversion: Patronage, Loyalty, and Conversion in the Religions of the Ancient Mediterranean, Berlin-New York: de Gruyter, 2004. Las consideraciones que siguen se apoyan en sus reflexiones, que se refieren más bien a la comprensión de la conversión de san Pablo (y otras conversiones recogidas en el Nuevo Testamento) a la luz de la ley de patronato. Cfr. también Elliott, J., «Patronage and Clientage», en RohrBaugh, R. (red.), The Social Sciences and New Testament Interpretation, Peabody: Hendrickson, 
prensión de nuestro tema. El intercambio y la reciprocidad eran claves de la cultura del patronato. El beneficiario del patrocinio respondía con la actitud de honrar al patrono, con agradecimiento y lealtad. En el mundo grecoromano este marco de ideas servía para concebir las relaciones entre el emperador y las ciudades, pero también entre un filósofo o maestros y sus discípulos, entre los dioses y los beneficiados por ellos, a los que han guiado, curado y salvado. Estas relaciones citadas tienen en común una asimetría, porque la recepción del don y el agradecimiento no están en el mismo plano, y las relaciones personales entre patrono y beneficiario no son iguales. Por eso, Séneca observaba que el patronato humano es un reflejo del patronato divino, lleno de generosidad interminable. San Juan Crisóstomo evocaba esta relación asimétrica al tratar del conocimiento humano de Dios, y señalar que los antiguos percibían de forma peculiar como un gran don divino incluso el mismo lenguaje (griego). No extraña así que la traducción griega de LXX sugiera la imagen de Dios como un benefactor romano, que otorga beneficios, y los lleva a su florecimiento (cfr. Sal 56,3; 2 Ma 6,13; Sab 11,5).

La Iglesia no busca un patronus en esta tierra (la carta de Santiago pone en guardia ante esta tentación), sino que tiene a Dios como único patrono, del que recibe tantos beneficios. En este sentido, los santos que reinan con Dios en el cielo son siempre «sub-patronos», si cabe hablar así. La conciencia de ser beneficiados, tan presente en las cartas de san Pablo ${ }^{29}$ (y subrayada por Tomás de Aquino en sus comentarios al Corpus Paulinum), se traduce así en términos familiares, donde las relaciones no son iguales, y se reconoce que todos los bienes son recibidos de arriba, del cielo. Tener un santo patrono para asuntos concretos pone de relieve esta dimensión doméstica de la Iglesia, como modo de reconocer y agradecer los bienes que se reciben.

\section{Sentido TEOLÓgico DEL PATRONUS}

Profundicemos ahora algunos elementos del contenido teológico de los santos patronos.

1996, 144-156; Neyrey, J., «God, Benefactor and Patron: The Major Cultural Model for Interpreting the Deity in Greco-Roman Antiquity», Fournal for the Study of New Testament 4 (2005) 465-492.

29 Cfr. Harrison, J., Paul's Language of Grace in its Graeco-Roman Context, Tubingen: Mohr Siebeck 2003, 110-112. Cfr. también Lampe, P., Paul, Patrons, and Clients, en Sampley, J. P. (ed.), Paul in the Greco-Roman World: A Handbook, Harrisburg: Trinity Press International, 2003, 488-523. 


\section{a) Dinámica de la intercesión}

Como hemos dicho, los santos que forman la Iglesia celestial actúan en favor de los peregrinos: las imágenes bíblicas, en particular el libro del Apocalipsis (Ap 8), subrayan el papel de los santos ante el altar del cielo que interceden por los vivos. Su función no sustituye la única mediación de Cristo, sino que se inscribe en ella. Son ellos quienes presentan ante Dios las oraciones de los peregrinos, sumándose a ellas con sus méritos, entendidos siempre bajo el primado de la gracia $^{30}$ : los dones del Señor se convierten en sus méritos. Sólo es posible concebir esta intercesión desde la perspectiva de la única intercesión de Cristo: los santos patrones participan de la única intercesión del Señor.

$\mathrm{Al}$ indagar la naturaleza de esta intercesión de los santos, Tomás de Aquino subrayaba que su influencia en nuestra salvación no es la de una causa eficiente, sino más bien la de una causa final: los santos pueden convertirse en causa del alterius agere pero no como quienes mueven directamente (por la coactio o por el imperio, precisa el Aquinate) ${ }^{31}$, sino como los que dirigen (ductores) mediante la ejemplaridad o mediante la intercesión.

En este sentido, elegir un patrón supone contar con la intercesión ante Dios de un santo con quien se mantienen vínculos por cierta semejanza con el camino cristiano en la tierra, en especial los mártires, que para la Iglesia primitiva eran los que se han ofrecido imitando a Cristo, con vistas al beneficio de todo el cuerpo de la Iglesia (y, como subrayaba Orígenes, su alegría no es plena mientras falte algún miembro del Cuerpo).

\section{b) Protección}

Uno de los beneficios que obtenía el «cliente» romano era la protección de su patrono. En el caso de los santos este servicio se cumple dentro de la Iglesia donde, según Rom 15,7, reina la regla de la acogida entre los cristianos a ejemplo de la acogida que se experimenta de Dios. Es interesante que santo Tomas de Aquino explicando este pasaje en su comentario bíblico lo profundiza con dos otras citas (de Lc 1,54 y de Is 42,1) que precisan el sentido de la

\footnotetext{
${ }^{30}$ En este contexto litúrgico se canta el Sanctus durante la Eucaristia: cfr. RouILLARD, P., «The cult of saints in the East and the West», en ChUPUNGCO, A. J., Handbook for Liturgical Studies, volume V: Liturgical Time and Space, Collegeville: Liturgical Press, 2000, 318.

31 Tomás De Aquino, In III Sent., d. 9, q. 2, a. 3, ad 7.
} 
acogida como protección y cuidado en el camino de la fe. Los santos (y tambien los ángeles) actúan desde fuera, mediante la persuasión, y no desde dentro, lo cual es una exclusiva prerrogativa de Dios. De modo que los santos pueden inspirar buenos pensamientos y excitar la pasión de apetito sensitivo, sin anular nunca la libertad humana. Dios provee así el camino de la salvación con su ayuda y custodia (también de los ángeles).

\section{c) Ejemplar}

Al tratar de los santos, Tomás de Aquino utiliza el término exemplum como algo más que un ideal que se ve reflejado en una vida santa. Por una parte, los santos muestran a los fieles viatores que el seguimiento de Cristo es «posible» en el contexto de su vida cotidiana: los patronos (con los que se siente una especial familiaridad) abren el espacio de lo posible a la fe ${ }^{32}$. Por otra parte, los santos constituyen una invitación a imitar lo que enseñan con su vida (ad instruendum). El Aquinate ve en el exemplum un proceso continuo de recibir la forma de Cristo que transmiten los hechos (gesta) de los santos, porque en ellos habla el Espíritu Santo; de modo que el ejemplo de los santos estimula a la constante re-forma de la vida ${ }^{33}$. La vida de los santos se convierte en «forma» $\mathrm{y}$ «precepto» de la vida cristiana, en la que se imita la vida de fe de un santo patrón y su devotionis exemplum, es decir, la entrega a Dios. De esta forma, el exemplum de los santos es más que un cuadro fijo de comportamientos para imitar mecánicamente, sino un exemplar, es decir, un caso particular o ejemplar del poder de Dios que actuó en su vida. Los santos se convierten en una «prueba» de la omnipotencia divina.

Para santo Tomás de Aquino también el cultivo de la teología o sacra doctrina está en relación con los santos: la teología participa en la ciencia de los bienaventurados en el cielo, en virtud de esta interna comunicación en la comunión del Cuerpo.

32 Duyndam, J., «Hermeneutics of Imitation. A Philosophical Approach to Sainthood and Exemplariness», en Poorthus, M. y SCHWARTZ, J. (ed.), Saints and role models in Fudaism and Christianity, Boston-Leiden: Brill, 2004, 7-21.

33 Tomás de Aquino, In Hebr., cap. XII, lect. 1. «Augustinus: sicut Spiritus Sanctus loquitur in Scriptura, ita in gestis sanctorum, quae nobis sunt forma et praeceptum vitae. Hoc est ergo exemplum sanctorum, quod inducit. Sed quia ad conformandum se ad aliquod exemplar, interdum ex impedimento superveniente impeditur homo, ideo removet illud quod potissime potest impedire». 


\section{d) Acompañamiento}

En los primeros siglos el término patronus designaba también las personas a las que se encomendaban los catecúmenos en su camino hacia el sacramento del bautismo, y también se ocupaban de los cristianos caídos (lapsi) en su regreso al seno de la Iglesia. Esta función se describía al inicio como la de un «protector» o «abogado» (advocatus), pero a partir del siglo VII se usó el término «patrono». Significativamente esta función reaparece en la exhortación apostólica «Evangelii gaudium» del papa Francisco, donde expone el arte del acompañamiento que debe caracterizar a cada cristiano y a la Iglesia entera: un seguimiento paciente que permite acompañar a las personas encomendadas en su crecimiento en la fe. Estamos ante una analogía con el caso de los santos patronos, que son aquellos que Dios nos propone como compañía en el camino hacia la Patria.

\section{CONCLUSIÓN: ¿NUEVAS PERSPECTIVAS DE UNA VERDAD ANTIGUA?}

Ciertamente hoy vivimos en un mundo diferente del medieval, que tenía gran sensibilidad hacia la dimensión comunitaria cristiana, sin disolverla en un colectivismo anónimo; más bien se articulaba el polo personal con el polo comunitario, integrando la biografía individual en la historia de la humanidad. Nosotros, en la actualidad, sufrimos la tendencia de percibir todo en perspectiva individualista. En cambio, el mensaje que transmite la fe en la comunión de los santos es que nunca estamos solos, sino siempre implicados en una red de relaciones dentro de la comunión eclesial. La Iglesia lo expresa de un modo particular en la liturgia, cuando apela a los que nos han precedido con la señal de la fe, y que ahora «duermen en la paz», sin que este «sueño» signifique pasividad o inactividad algunas. Más bien se anima al fiel para que en su camino hacia el cielo cuente con esta ayuda de Dios mediante los santos, que nos invitan a la alegría eterna que ya goza la Iglesia triunfante. Un santo patrón acredita que es «posible» vivir cristianamente mediante su ejemplo y con el auxilio de su intercesión en el camino de la vida. 


\section{Bibliografia}

Badian, E., Foreign Clientelae, Oxford: Clarendon Press, 1958.

BAJO, F., «El patronato de los obispos sobre las ciudades durante los siglos IVV en Hispania», Memoria de Historia Antigua 5 (1981) 203-212.

Balthasar, H. U. von, Kim jest chrześcijanin?, Kraków: WAM, 1999.

Berardino, A., Diccionario Patrístico y de la Antigüedad cristiana, Salamanca: Sígueme, 1998.

BERRY, J. A., «What make us human? Augustine on interiority, exteriority and the self», Scientia et Fides 2 (2017) 87-106.

BROWN, P., Il culto dei santi: l'origine e la diffusione di una nuova religiosità, Turin, 1983.

CANALI DE ROSSI, F., Il ruolo dei patroni nelle relazioni politiche fra il mondo greco e Roma in età repubblicana ed augustea, Munich-Leipzig, 2001.

Chapman, A. A., Patrons and Patron Saints in Early Modern English Literature, New York: Routledge, 2013.

Crook, Z., Reconceptualising Conversion: Patronage, Loyalty, and Conversion in the Religions of the Ancient Mediterranean, Berlin-New York: de Gruyter, 2004.

De Silva, D. A., Honor, Patronage, Kinship and Purity: Unlocking New Testament Culture, Downers Grove, IL: InterVarsity Press, 2000.

Duyndam, J., «Hermeneutics of Imitation. A Philosophical Approach to Sainthood and Exemplariness», en PoOrThUIS, M. y SCHWARTz, J. (eds.), Saints and role models in Fudaism and Christianity, Boston-Leiden: Brill, 2004, 7-21.

Elliott, J., «Patronage and Clientage», en Rohrbaugh, R. (red.), The Social Sciences and New Testament Interpretation, Peabody: Hendrickson, 1996, 144-156.

Harrison, J., Paul's Language of Grace in its Graeco-Roman Context, Tubingen: Mohr Siebeck, 2003.

Kasper, W., Teología e Iglesia, Barcelona: Herder, 1989.

Kaufman, R., «The patron-client concept, and Macro-Politics: Prospects and Problems», Comparative Studies in Society and History 3 (1974) 284-308.

Lampe, P., «Paul, Patrons, and Clients», en Sampley, J. P. (ed.), Paul in the Greco-Roman World: A Handbook, Harrisburg: Trinity Press International, 2003, 488-523. 
Lentino, F., Patron, en Di Berardino, A. (red.), Encyclopedia of Ancient Christianity (2014).

Martínez, M. A., Estados o fases de la Iglesia, en VILlar, J. R. (coord.), Diccionario de Eclesiología, Madrid: BAC, 2016.

McGrath, A., Re-imagining Nature. The Promise of Christian Natural Theology, Oxford: Wiley-Blackwell, 2017.

NeYReY, J., «God, Benefactor and Patron: The Major Cultural Model for Interpreting the Deity in Greco-Roman Antiquity», Fournal for the Study of New Testament 4 (2005) 465-492.

OrSELLI, A. M., «Il santo patrono cittadino fra Tardo Antico e Alto Medioevo», en La cultura in Italia fra Tardo Antico e Alto medioevo, Roma: Herder, 1981, 771-784.

Osiek, C., «The Politics of Patronage and the Politics of Kinship: The Meeting of the Ways», Biblical Theology Bulletin 3 (2009) 143-152.

Roszak, P., Credibilidad e identidad. En torno a la teología de la fe en santo Tomas de Aquino, Pamplona: Eunsa, 2014.

RoullLard, P., «The cult of saints in the East and the West», en CHuPUNGCO, A. J., Handbook for Liturgical Studies, volume V: Liturgical Time and Space, Collegeville: Liturgical Press, 2000.

Saller, R., Personal Patronage Under the Early Empire, Cambridge: CUP, 1982.

STEEVEs, N., Grâce a l'imagination. Intégrer l'imagination en théologie fondamentale, Paris: Cerf, 2016.

SzCZANIECKI, P., Sacramentum dedicationis. Obrzęd poświęcenia kościoła i jego znaczenie w dziedzinie religijnej, obyczajowej $i$ kulturalnej na podstawie źródet polskich z XII wieku, Lublin: TN KUL, 1979.

Toniolo, A., Arocena, F. M. e Ivorra, A., Concordantia missalis hispanomozarabici, Roma: LEV, 2009.

TureK, W., «Patron saint», en Di Berardino, A. (ed.), Encyclopedia of Ancient Christianity, Downers Grove, IL: IVP Academic, 2014.

Wallace-Hadrill, A., Patronage in Ancient Society, London: Routledge, 1989. 

RECENSIONES 
